\title{
CDISC SDTM Directly Observed Therapy Location Terminology
}

National Cancer Institute

\section{Source}

National Cancer Institute. CDISC SDTM Directly Observed Therapy Location

Terminology. NCI Thesaurus. Code C102576.

Terminology associated with the directly observed therapy location codelist of the Clinical Data Interchange Standards Consortium (CDISC) Study Data Tabulation Model (SDT M). 